Lepr Rev (1990) 61, 97-111

\title{
Editorial
}

\section{REDEFINING HEALTH EDUCATION IN LEPROSY: A PERSONAL VIEW}

Most textbooks and published guidelines on leprosy state that health education is a requirement for leprosy control or makes an important contribution to it. Similar views are expressed at international conferences on leprosy and in discussions with field staff.

Despite these statements, while training leprosy workers in health education.* I have been faced with a number of unresolved issues. These are not confined to any particular country and emerged in workshops conducted in West Africa, East Africa and South East Asia. In my opinion, four of them need urgent attention. Let me briefly state them.

First, health workers expect health education to solve questions of misunderstanding about leprosy, but also to radically change beliefs and practices of communities with respect to the disease and its sufferers. Health education should make the defaulter not default, the ulcer patient to rest his limbs, the discharged patient not to claim further medicine and so on. Are such expectations realistic or, more to the point, are they justified?

To answer the question we need to examine the assumptions made by health workers about the nature and practice of health education and to see whether they are in agreement with what is currently known about the field and accepted by its practitioners. I will argue that many health workers tend to assume that health education in leprosy is mainly concerned with dispensing facts about the disease and its treatment. I will then discuss three assumptions about health education practice which all health workers should be familiar with and which constitute a framework to define health education in leprosy.

A second issue concerns the deficiency in health workers' skills in communication and human interaction.

Health education activities at treatment sessions or health talks for village groups tend to-be 'one-way messages'. It is common to hear health workers ask: 'How can we make our talks more attractive? Should we use other media? Why are we receiving so little feedback from patients? Why are our patients forgetful? Why don't we see much evidence of changes in patients' behaviour?' Some health workers become discouraged and medical officers and supervisors report a lack of interest among health workers to health educate patients and families. Nevertheless, health workers are very much aware of the 'precept'

* Since 1984, Workshops on Health Education in Leprosy have been conducted for 20 to 25 participants (medical officers, supervisors and paramedical workers) at national or district level in the following countries: Côte d'Ivoire, Sierra Leone, Burkina Faso, Mali, Congo, Tchad, Senegal, Niger, Madagascar, Ethiopia, Pakistan and India. 
that health education 'should' be given to patients and communities. It is not just a popular activity.

In my view the current gap between 'precept' and actual communication 'performance' is based on a misconception about the acquisition of communication skills and, on the ways in which health workers have been trained in medical schools or in schools for paramedical workers. I will then propose how skills in communication and human interaction can be improved.

Thirdly, despite the emphasis on health education to achieve leprosy control objectives, few leprosy control programmes make administrative provisions to support and reward health education activities. Managers of leprosy control programmes have questions about: who should provide health education and where should it be done? What type of set-up is required to develop, support and monitor health education activities of staff? What guidelines are available or should be proposed to leprosy staff working in outpatient departments, field clinics, rehabilitation departments and hospital wards?

In order to answer some of these questions we need a common view and a set of principles about what constitutes health education in a leprosy control programme. Towards that end I will set out three principles of health education and discuss their implications for leprosy programme organization.

Finally, I find that available research on health education or on social science issues in leprosy does not provide the insights health workers need to justify their approach towards patients and communities. For example, health workers will ask: how can we change the traditional beliefs of patients which are harmful because they delay early detection? Or how should we handle a patient who denies he has leprosy? How can we be more successful in teaching self-care in our clinics to patients with loss of sensation in hands, feet or eyes? Can we change some of the unfair ways in which communities treat leprosy patients?

In my view social science and health education research should focus less on cultural particularities of leprosy care in different countries and more on 'basic themes' related to the psychosocial mechanisms and processes used by patients to give meaning to their disease and make decisions about care. These themes are strikingly similar in different countries. I will propose three orientations for research studies so that health workers are able to formulate a more reasoned explanation for their work instead of proceeding on the basis of an 'intuitive' grasp of the problem.

Let me now turn to a separate discussion of the issues.

\section{Need for a framework}

\section{INFORMING PATIENTS AND ORGANIZING CAMPAIGNS}

In countries that I have conducted workshops, I found two prevalent views about the nature and practice of health education. First, health education is seen as informing patients about accepted medical facts concerning leprosy (its cause, spread, symptoms, progression, prognosis, treatment and rehabilitation). Secondly health education is seen as organized campaigns in urban or rural settings aimed at raising awareness about the disease or at combating social stigma.

These views are correct but incomplete. They are limiting by not adequately explaining why certain problems arise and what suitable strategy should be employed. 
Their limiting character stems from two underlying assumptions: that enlightenment of patients or the public is a sufficient condition to change their behaviour; and that such enlightenment is achieved by one-way communication.

Most health workers agree that these assumptions are inadequate to understand and deal with problems of late detection, defaulting, self-care or social stigma. Yet why is it that in the practice of leprosy work health education is still largely based on those assumptions? One reason may be historical.

Informing, convincing and exhorting population groups to avail themselves of new insights about common illnesses and their treatment and to apply these insights to daily life, was the major task of public health workers in Western Europe in the early 20th Century. No one doubted the soundness of this strategy. The strategy and its underlying assumptions were passed on to successive generations of health workers through curricula in schools of medicine and public health. Even today most curricula maintain that unhealthy ways of life should be altered by a combination of social pressure (laws, regulations) and the enlightenment of the public.

Another reason may be that some of the major publications on leprosy unwittingly reinforce a limiting outlook on health education. For example, Jopling's Handbook of Leprosy, p. $82^{1}$ refers to health education as: 'propaganda to dispel ignorance, fear and prejudice'. Films on leprosy are suggested as a main tool to provide adequate information to health workers and the public (op. cit. p. 116). Thangaraj's and Yawalkar's text on Leprosy for Medical Practitioners and Paramedical Workers, p. $95^{2}$ states the following: 'Health education of the patients and the public should be organized on an intensive scale . . . . . the enlightened participation of the whole population is essential .... And a leading French textbook on leprosy by Pattyn et al. p. $58^{3}$ does not mention health education at all although the section on how to organize leprosy control is quite detailed. Reference is made to the importance of a good doctor-patient relationship in obtaining drug compliance.

Bryceson \& Pfaltzgraff's ${ }^{4}$ accessible exposé on leprosy has no explicit reference to health or patient education but the authors are aware of the psychosocial reality of leprosy. This is evident in the section on 'Rehabilitation' which discusses physical, psychological and social strategies (op. cit. p. 114). The book on leprosy edited by R S Hastings ${ }^{5}$ has one page on health education under the heading 'Control Programmes' it is mainly a summary of WHO's thinking about the aims and principles of health education (op. cit. p. 261). However, considering the size of the textbook (319 pages) this one-page reference is a meager treatment of the subject.

Fortunately, publications in the 1980's start to reflect a different view on health education in leprosy. For example the ILEP booklet on Guidelines for the Campaign against Lepros $y^{6}$ carries a succinct and readable statement about aims and requirements for health education in leprosy (op. cit. pp. 12-3). Similar good advice comes from Pearson ${ }^{7}$ who summarizes the main principles of health education in leprosy and further states that, 'health education is not merely instruction or one-way communication' (op. cit. p. 42).

The 1988 Guide to Leprosy Control $^{8}$ by the World Health Organization provides a fairly balanced view on health education in leprosy. The section on health education (op. cit. pp. 62-4) goes beyond the view that health education consists of explaining facts about disease and treatment. It draws our attention to four specific points: health education can be required for patients, their families, for health workers and for 
communities. As a method it is needed at all stages of leprosy control. It is a duty for all health workers, and good health education practice requires an understanding of the psychological and social situation of the patient.

\section{A modern view of health education}

We define 'Health education as a set of activities based on processes of communication and learning and designed to help people decide to behave in a healthy, not harmful way'. There are three main assumptions underlying such a definition?

\section{HEALTH BEHAVIOURS AND HEALTH OUTCOMES}

First, we assume that what people do is relevant to their health, either positively (taking prescribed drugs, wearing sandals, continuing to work or to stay in one's household) or negatively (defaulting; moving to another area without notifying health staff). The consequences of particular decisions people make are reflected in the state of their health, such as, the early or late detection of cases in an area, the rates of compliance and of deformity, measures of social integration. Thus not only 'physical events' (size and number of patches, degree of nerve damage) but also 'behavioural events' determine health outcomes.

The relationship between what people do and their health constitutes the justification for health education. Without such a relationship health education is not needed nor justified. In other words there is no health education problem.

Therefore, health workers should be able to state for any health problem that they are working on, its behavioural ref erence point. For example, when you give a health talk to a group of teachers to increase their awareness of early signs of leprosy, behavioural reference points may be that school teachers fail to teach children about early signs of leprosy or do not present themselves readily to a health worker, or do not encourage any other person to do the same.

The ability of health workers to define health education problems can be sharpened by analysing case histories. A case history reveals the profile of decision-making by the patient, his relatives and of ten the surrounding community.* It is useful for health workers to reflect on those decisions in terms of the consequences of these decisions for early detection and complete treatment.

Key decisions in leprosy (alternatively called 'normative', 'critical' or 'prescriptive' behaviours $\dagger$ ) of patients and communities are listed in several publications. ${ }^{6,8-12}$

* In the Workshops on Health Education in Leprosy participants are requested to interview a patient and to elicit a narrative account of what the person has done from early signs to the current stage of his treatment. Emphasis is placed on how the patient views his illness and care, on his decisions and on his social network. Examples of such case histories can be found in 'The Manual on Health Education in Leprosy'.

$\dagger$ 'Normative' behaviour is used in the sense that there is a consensus among health experts about what constitutes proper individual and collective behaviour to prevent and control a particular disease. Some normative behaviours are debatable because of insufficient evidence concerning their relationship to the outcome of health or because of conflicting values society concerning the proposed behaviour. This is especially the case for sensitive areas such as sexuality and family planning. 
Sometimes they are grouped together under the heading 'participation in leprosy care' calling our attention to the fact that health workers advise, people decide.

\section{CHANGING HEALTH BEHAVIOUR THROUGH EDUCATION}

We assume that we are able to modify people's decisions through health education. That behaviours change is a fact of daily life. Why they change is a different story and still more elusive is the question, how we can contribute to changes which are positive to a person's health. Research and practice indicates that we need not be unduly pessimistic or optimistic about behaviours and their change.

What people do for their health is far less stable than is usually thought. Case histories illustrate this point clearly. For example people with a patch will try a 'remedy', then abandon it, then try another one, or change their minds again and now follow a friend's advice, or they show up at the clinic and so on.

Another point is that the decisions we are talking about (i.e. voluntary and conscious decisions) are not made at random but are influenced by a set of specific forces of differing strengths. For example, the decision to default can be based on lack of perceived improvement in health condition, traditional beliefs suggesting another approach (going to Holy Water, offering prayers in the Temple), financial needs, difficult access to health services, conditions of climate or geography, or a lack of trust in the health worker. We should find out which forces are dominant for a particular patient and adjust our approach accordingly.

A last consideration about changing people's decisions relates to the intrinsic nature of health education activities. The health education approach, as compared to legislative measures or structural changes, is specific in that it activates a learning process to obtain changes in decision and behaviour. This of course limits the potential of health education to influence decision making about health. We are all aware that we may stop smoking cigarettes in places where smoking is forbidden; that the type of service offered to leprosy patients may determine how they feel about themselves as leprosy patients, how independently they will pursue their own life projects or how much they will remain in the charge of the community.

The practical significance of the above is that different types of strategies should complement each other or, conversely, not to expect health education to be the only strategy able to affect changes in decision and behaviour.

\section{PRINCIPLES OF COMMUNICATION AND LEARNING}

A third and last assumption states that methods of health education follow a set of general rules and principles which can be laid down, learned, applied and validated.

The central reference point for all methods of health education is their contribution to effective learning. Therefore rules and guidelines will be derived from our knowledge of the communication and learning processes. In practice, I have witnessed examples of ineffective health education because of insufficient insight into conditions which affect communication and learning. For example, long explanations to a patient who is sick or tired; dispensing audiovisual messages in noisy and crowded waiting rooms; diffusing messages to a general and not a specific target group. In the next section on skills in communication and human interaction, I will discuss some of the general rules of communication and learning. 


\section{Overcoming three deficiencies in communication and human interaction}

Communication is health education's major tool. It therefore needs careful consideration.

In the field and at workshops I have observed different levels of communication skills among health workers. Three deficiencies are readily apparent.

\section{COMMUNICATION AS TALKING}

First, most communication by health workers, be it in clinics, villages or wards, is confined to talking. Patients are instructed about medication and follow-up visits; they are taught self-care measures for insensitive hands, feet and eyes; advice is given about work and about continuing family relationships. However, what is not used in educating patients are the concurrent skills in listening, observing, using non-verbal signs and symbols. These skills are as much a part of communication as talking.

It is a fundamental rule of communication that it is impossible not to communicate. ${ }^{13}$ In other words, all interactions between health worker and patient (or public) have 'communication-value'.

Imagine, for example, that you are a patient and you come to the health worker's desk who is busy filling out his records. You will have received communication even without a word being uttered. Another example. A patient comes to the clinic and starts by saying: 'Doctor, I have been taking these tablets for two months and I don't see any improvement'. Many health workers will reply: 'Don't worry; be patient; continue taking your medicines'. Some will even turn suspicious and ask, 'Have you been taking your medicine?' None of these replies are advisable because they show that the health worker is not 'listening' to what is on patient's mind. He could start by saying: 'You want to talk about this?' or 'You don't see any improvement?' or other 'open' listening responses.

Also observation skills are not properly used. They are easily confused with interpretation. When health workers are asked, for example, to describe a patient they have observed they may say: she wore a green dress; she had a patch on the upper left arm; she was depressed. How did they know she was depressed? What did they look for and see? Perhaps the patient said something; had a particular facial expression; walked slowly; hunched her shoulders?

Talking, observing and listening interact and influence each other. It is the mastery of these three elements for a specific purpose (an interview, a health talk ...) that characterizes an effective communicator.

\section{COMMUNICATION AS CONTENT}

A second problem that health workers have in communicating with patients or the public is a too exclusive emphasis on the 'content' of the communication, i.e. the ideas or advice the health worker wants to pass on.

A knowledge of the correct facts is important. However, it is only part of what makes communication effective or ineffective. The other part, which is intrinsically present in all forms of communication, has to do with the way in which a health worker, or for that matter a patient, wants his message to be understood. So people always communicate on two levels: the idea and how I want you to understand the idea. The last part is technically called meta-communication. ${ }^{13}$ Full exchange of meaning between sender and receiver, 
which is what communication is all about, occurs when both health worker and patient are tuned in at both levels. For example, a health worker tells a patient, 'I want you to take these tablets'. The patient will understand that the health worker talks about 'tablets', and not about surgery, or hospital admission or preventive measures. However, the impact of the idea on the patient will depend on how he interprets the meta-communicative part of the message. Specifically, how strong is the 'appeal' in this message? What does the message reveal about the health worker as a person? Is he expressing concern or anger? This is the 'expressive' function of a message. Also the message about tablet taking is formulated in the context of a specific relationship between health worker and patient. If the relationship is distant or formal, the message, 'I want you to take these tablets', will be perceived more as an order. If the relationship is less distant and both respect each other, and the health worker wants the patient to decide, then the message is more likely to motivate a patient to take the tablets.

The health worker or patient may not be clearly aware of the meta communicative aspects in communicating. However they are present in all human interactions and influence communication effectiveness. They are most clearly revealed when health worker and patient face communication problems. For example, a patient does not fully trust the health worker. A health worker is annoyed with a patient who reveals little about himself. An instruction lacks appeal. We sense instinctively that trust, annoyance, lack of expression or appeal will affect the message. Therefore, we should learn to identify these aspects of communication and apply them in our health education work.*

\section{COMMUNICATION AS ONE WAY TRANSMISSION}

Health workers have difficulty in formulating advice, instructions and explanations from the patient's or the public's point of view which is called 'receiver-orientation'. For example, when we advise a patient do we consider what it means to him to take drugs every day for six months or two years? What about advice on wearing sandals for insensitive feet? Do we think about how a farmer or a young lady look at the prescribed advice?

More receiver-orientated health workers will spontaneously make their message more attractive. They will use words the patient uses himself, discuss contra-arguments to wearing sandals (and not brush these arguments off as irrelevant), demonstrate and give feedback, use examples, listen to patient's objections and practical concerns. However, some health workers do not sense what a receiver-orientation is or they do not know how to put it into practice. The result is one-way communication from a 'health worker' perspective. Such communication is ineffective and does not satisfy either health worker or patient.

WHY DO THESE DEFICIENCIES IN COMMUNICATION SKILLS EXIST AND WHAT CAN BE DONE?

Knowledge about the rules, principles and practice of effective communication exists and has been validated in situations of business relationships, mental health counselling, and

\footnotetext{
* The Workshop on Health Education in Leprosy comprises specific training modules on communication skills where health workers learn to identify and correct specific deficiencies in this area.
} 
marketing. However, curriculum analysis of training programmes in different countries shows that little or next to nothing is being taught about communication and human interaction to health workers.*

In my view this situation is related to two misconceptions about communication skills for health workers.

Some feel that since communication is part of human life it is acquired naturally and should not be learned. Differences in communication skills are explained by differences in basic personal aptitudes, about which not much can be done.

The other misconception relates to an overestimation of the traditional clinical method. Mastery of the clinical method by health workers is considered sufficient to deal with the essential requirements of patient care and community health. So, health workers should be able to detect and interpret signs and symptoms of disease, know the tools for gathering clinical evidence, be able to arrive at proper diagnostic conclusions and to apply proper treatment.

I do not question the power and efficacy of the clinical method as learned by health workers. However, I do question the claim that mastering the method is sufficient to effective patient and health care.

First, the method focuses on physical events only which are relevant to detect and follow the disease processes. But illness or 'dis-ease' cannot be reduced to physical events. Having leprosy cannot be reduced to bacilli, or to their damage to the peripheral nerves, the state of body immunity and so on. Having a disease is a psychosocial event. People give meaning to their signs, symptoms and misfortunes. Communities react to diseases; and differently to malaria than to leprosy.

Secondly, traditional medical circles do not ignore psychosocial events but place them in a loosely defined category of 'bedside manners' or natural empathy for patients without acknowledging that such events can be properly identified, classified or that skills can be learned to deal with the non-disease aspects of a person's health problem. The main reason for not taking these events more seriously is that they are not considered 'scientific', i.e. open to observation and verification. This is nonsense. A person's behaviour is as open to objective scrutiny as a bacillus under a microscope. In this respect we may want to heed Cassell's observation on medicine's twin goal which is to cure disease and to relieve suffering: 'Considering that medicine's warrant to exist is (also) to relieve suffering, a profession grounded in the belief that it cannot have real knowledge of whether someone is suffering has lost its way' (in Stewart \& Roter, ${ }^{14}$ p. 15).

How then can we improve the communication skills of health workers? A first and general requirement is accepting the limiting nature of the traditional clinical method based on a 'biomedical' perspective and the need to pass on knowledge and tools to health workers to deal more effectively with the psychosocial reality of disease and health. A second requirement is the organization of training in the health education and social aspects of leprosy for health workers in basic and in inservice training programmes.

The Workshops on Health Education in Leprosy may serve as a useful model for their adaptation is being discussed by the ALERT and Karigiri Training Centres. However, not all health workers attend regional training centres. Some are trained at national level (e.g. MAC in Pakistan), others may receive inservice training at district

\footnotetext{
* There is an encouraging new trend in selected schools of medicine and institutes for paramedical workers and a resurgence of interest in the process of communicating with patients. ${ }^{14}$
} 
level. Therefore from 1990 onwards the training of selected health workers as 'future teachers' in health education is being organized.

Attention to inservice training only has a drawback in that much time is spent to 'unlearn' specific habits picked up from teachers and mentors during basic training. It is therefore advisable to include teaching modules on the health education and social aspects of leprosy as part of the current efforts reported by McDougall and Georgiev to introduce basic leprosy teaching into the curricula of medical students and other cadres of health personnel. ${ }^{15}$

\section{Funding a place for health education in leprosy control programmes}

What health education activities are implemented in leprosy control programmes? We have no reliable information on the subject. Current reporting through the annual ILEP forms is incomplete and misleading. If activities are reported they tend to be those which are highly visible and which can be stated quantitatively. For example, a programme has conducted a large-scale leprosy awareness campaign in Madras or in Bombay; 50 talks have been held in schools in Control Area 3 of Sierra Leone; 10 meetings about leprosy have been arranged with medical and nursing societies in Karachi. Other reported activities may include World Leprosy Day events, participation in health fairs, leprosy messages sent through press, radio or TV.

But much health education goes unreported, especially patient education during home visits, in clinics, in physiotherapy departments.

A first step should be to obtain a better picture of current health education activities and needs. I suggest regional meetings of programme directors as a tool for data collection since there is no commonly accepted terminology for the coding of health education activities, making written reports therefore unreliable.

Most leprosy control managers I have met in different countries want to include health education activities in the programme, but have questions about the effectiveness of current activities; about who should be responsible for health education and about where and how to introduce health education in the scheduled activities of the leprosy control programme.

These questions should be discussed and answered within the framework of three principles.

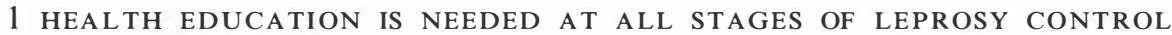

Health education in leprosy tends to focus on problems of late detection or on the teaching of self-care for the prevention of deformities. I suggest we define health education activities in other areas as well, such as the first contact of people with leprosy services for diagnosis and eventually treatment. Health workers should provide proper conditions for communication to help new patients accept the disease and the proposed treatments.

Another area is the promotion of regular treatment and ensuring appropriate postsurveillance behaviour among patients. Are proper communication skills applied? Does the clinic setting and its organization favour effective communication between health 
workers, patients and relatives? Finally, what is being done educationally to prevent social isolation of leprosy patients? Are problems of family or of community support sorted out?

Thus health education contributes to effective leprosy control in the following areas: through promoting early detection, helping with the acceptance of disease and treatment, ensuring regular treatment and appropriate follow-up; preventing deformities by teaching self-care and preventing social isolation. These are the major headings under which we should define specific health education practices.

Examples of successful practice in those areas are scattered throughout different leprosy programmes. It would be useful to exchange and share these experiences amongst leprosy control managers and people interested in health education in leprosy.*

\section{ALL HEALTH WORKERS INVOLVED IN LEPROSY WORK ARE HEALTH} EDUCATORS

This statement is deceptively simple but contains important implications for the organization of leprosy programmes.

I will first discuss the common practice to appoint one or two persons in a leprosy programme who carry the title 'health educator' and who are officially charged to conduct health education activities; then the requirements of an 'integrated approach' where all health staff perform health education tasks.

Appointing a special health educator is not an advisable arrangement. It is impossible for one person to carry out the health education functions specified in the abovementioned programme areas. Secondly, it de-motivates other health staff to health educate whenever they see a need amongst patients they care for. Furthermore, the practice of referring patients who have a 'health education problem' to a special health education section does not make good educational sense. Patients and families with learning needs want them to be solved by the health worker they know and have come to see as their resource.

Is there then a place for a specially appointed health educator? The answer is a qualified yes, provided he/she is a respected capable and experienced leprosy worker and provided the health education duties are of the 'support' and not of the 'delivery' type. Examples of support activities are: organizing inservice training for health staff on communication skills or on how to organize group sessions; developing teaching materials for staff in field clinics, OPD, physiotherapy; assessing progress or problems in the health education performance of staff and assisting the programme manager and the field staff to organize specific activities in the community, including campaigns.

How to make a strategy succeed whereby all health staff participates in health education at their own level of work?

I am not aware of any reported experience of leprosy programmes with fully integrated health education services. However, feedback from workshop participants indicate two conditions: a sufficient level of training of staff in communication skills and the provision of administrative support to apply those skills with patients and

* A beginning of sharing of programme experience was initiated at the International Leprosy Congress, The Hague, 1988. During a pre-congress workshop 15 participants, leprosy control managers and health educators from 12 countries, discussed issues concerning health education work in leprosy programmes. The proceedings of the Workshop, published in an 80-page booklet, are available from TLMI, Brentford, UK, ${ }^{16}$ free of charge. 
communities. Support requirements may vary from the need for teaching materials, to transport, to rearrangement of patient load. In my opinion there is no standard solution. Possible arrangements should be discussed on their merits within the context of the programme.

I would like to add a third condition which also has been raised by some programme managers: the need to provide health workers with standardized guidelines for health education work in a number of situations, very much in the same way as guidelines exist for skin smear taking or VMT assessment.

Some programmes have made headway in this regard. For example, the Marie Adelaïde Leprosy Centre in Karachi published a Leprosy Skill Book, ${ }^{17}$ containing guidelines for health education tasks and also forms to be filled out by leprosy workers (National Training Institute MAC). The Leprosy Control Programme of the Phillipines has developed detailed sets of tasks for multipurpose health workers on leprosy, including health education tasks. ${ }^{18}$ Such work should be shared with other control programmes and reviewed for applicability in other settings. Furthermore, a few texts with advice to health workers on how to conduct health education, are available. Jane Neville's Guide to Health Education ${ }^{10}$ in leprosy is well known and Jean Watson's book on Preventing Disability in Leprosy Patients ${ }^{11}$ has a fine section on patient teaching (op. cit. 97-106). Guidelines for health workers' educational tasks in specific situations such as promoting early detection, acceptance of disease, drug compliance and prevention of deformities, have been prepared as hand-outs for participants of the Workshops on Health Education in Leprosy. ${ }^{19}$ However, most guidelines need further refinement and especially validation.

Two final notes on the place of health education in leprosy control programmes.

What would be a proper administrative focal point for health education? Currently, focal points exist in Departments of Physiotherapy or Ergotherapy (ALERT, Karigiri) or at the central office level (Sierra Leone). In view of the supportive function of a specialized person I would argue not to place such a person in a particular section of the programme but to associate him with the training department or with training activities.

Secondly, our discussion on where to place health education activities in leprosy programmes should be seen in the context of changing patterns of programme organization due to the introduction of MDT requirements and to the integration of leprosy services in primary health care systems. It is said that a reduced caseload will provide more time for community education and for working on issues of social rehabilitation. I am sceptical about this, unless we witness a radical change in the views of programme managers and health workers from a biomedical to a psychosocial perspective.

Integration or linkage of leprosy services with other health services will considerably expand the volume of health education work as communication will be needed to address several priority diseases. In my opinion, if a good job is done on health education within the leprosy control programme, the extension and/or integration will not pose great problems because principles and strategies of health education in leprosy apply to other diseases as well.

\section{HEALTH EDUCATION PRACTICE SHOULD BE BASED ON RESEARCH}

I will discuss this point under the next heading. 


\section{Refocusing research on health education and social aspects of leprosy}

Two recent papers in the International Journal of Leprosy have reviewed health education and social science research in leprosy. ${ }^{20,21}$ In my opinion, a distinction between health education and social science research is not meaningful since there is none. Both focus on the cultural, socioeconomic and psychological problems related to leprosy. Health education research will perhaps focus more on communication methods while social science more on stigma and culture, but these are matters of degree, not of substance.

Most research studies are based on questions such as: why are patients defaulting? What knowledge, misconceptions and fear exist in communities about leprosy? What is stigma? How is it expressed? What are the effects of awareness campaigns on leprosy knowledge and early detection?

Reflecting on these studies in terms of their usefulness to health education practice and to communication activities of health workers, I would say: a, that too much attention has been given to research on the outcome (e.g. defaulting) and not enough to the underlying processes (e.g. what is the coping mechanism of a patient which explains his defaulting); $b$, the patient has been over-researched and more attention should be given to the health worker as a focus of research attention; and c, cultural differences receive considerable attention in research studies, such as, what different people believe to be the cause of leprosy, but what strikes me more is the 'similarity' in different countries of basic mechanisms explaining patient and community beliefs and behaviour.

I would suggest three lines of research.*

1 We need studies of basic processes which guide individual and community decisions about leprosy. Two themes merit attention: an investigation into belief systems and strategies of their modification; and studies about the nature of coping with leprosy and its treatment.

There is evidence of a new way of looking at beliefs about leprosy and about the use of simple tools to assess those beliefs in the social and cultural matrix of a community. ${ }^{22}$ Still health workers need to know more clearly what, if anything, they can do about existing beliefs. Beliefs are not curious aberrations from a biomedical explanatory perspective nor caused by ignorance of the patient. If they are vital elements to people in helping them to make sense of unexpected events (such as signs, symptoms), how do you approach them? More particularly, can one influence a belief-system and if so, how?

Studies about coping as a psychodynamic mechanism for guiding a patient's responses towards illness and care would be useful to make sense out of observed decision profiles of patients. These studies could also suggest fruitful approaches health workers can take at particular stages of a patient's disease.

Patients have their own ways of dealing with illness and misfortune and their behaviours are not at random. They follow what Senkenesh calls 'care seeking stages'. ${ }^{23}$ These stages are adaptive or coping responses to an illness as well as to the proposed care (treatment, surgery, the health worker, an institution). They represent a process every person goes through.

Such stages have been identified for diseases such as cancer. ${ }^{24}$ Identifying similar stages for leprosy would be useful. The health worker would have a better insight into

* A more detailed account of research priorities on health education in leprosy control is available as an internal 4-page document submitted to ILEP, May 1989. 
problems which occur such as, non-acceptance of the disease; patient's use of other healers; his claiming of drugs after discharge, and so on. Such behaviour of patients would then not be considered in isolation (requiring, as of ten is thought, an extra dose of health education) but as an expression of a coping response which requires a specific and appropriate approach. For example, a health worker when faced with a patient who is complaining that his patches are not disappearing and that he does not feel well will tend to respond with a 'don't worry, after a few more months the patches will disappear'. In fact, the health worker should understand that the patient is going through an accommodation stage of his illness and is re-assessing the meaning of his disease within the context of his personal life projects. Armed with this knowledge health workers could initiate a discussion on personal concerns about the consequences of the disease on a person's life rather than to suggest not to worry.

In a more general sense, unless we better understand the nature of suffering of a person, we are not able to help effectively. On the contrary, health workers who fail to understand the nature of suffering can engage in medical interventions that (although technically adequate) not only fail to relieve suffering but may become a source of suffering itself' ${ }^{25}$

2 A second line for research should focus on the health worker. It has been suggested that health workers may contribute to misconceptions and fear about leprosy. ${ }^{21}$ If so, it is an important observation requiring closer analysis and possibly a review of current training practices.

Several studies acknowledge the possible beneficial effect of a sound health workerpatient relationship with respect to patient attendance, drug compliance and other indices. Yet can we describe the parameters of a sound relationship? How do those with a sound relationship behave compared to those with an ineffective relationship? How much do we know about the attitudes of health workers towards patients compared to the amount of research on the attitudes of patients towards disease and care? And, what about studies of job satisfaction and commitment of the health worker towards leprosy care and particularly towards the educational and social aspects of his task? We know little about this area. Yet a satisfied worker is an effective worker.

3 A third and final area for research which I would like to suggest deals with the evaluation of communication strategies and methods.

Although we possess an interesting set of rules and principles for communicating with patients and communities, several communication practices need validation. For example, how do we translate medical concepts into words and a language people readily understand? Is 'health belief synthesis', which attempts to bridge the gap between scientific and cultural concepts about leprosy, an effective procedure? ${ }^{26}$ Another research theme concerns the specifics of community participation strategies. What are the steps? Are there simple tools to assess opinion leaders and the influence of social networks in decision-making? Who are the main informants about leprosy and its care? What is the role of traditional healers in this respect? What types of relationships are viable between leprosy services and healers?

\section{Conclusion}

I have discussed the need to redefine health education in leprosy. Some of the thoughts expressed in this paper may be useful to programme managers and health workers. They 
are intended for discussion and comments. In my opinion, a redefined view on health education will help reduce unrealistic expectations about health education in leprosy, provide health workers with effective tools to do their educational work, ensure a supportive programme structure and increase our understanding of basic themes which not only cut across cultural variations but also will influence the way in which people are cared for.

Does ILEP have a role in all this?

Being a coordinating body to ILEP-member associations, ILEP could for example, promote and coordinate health education activities in leprosy; secure expert advice on this matter to leprosy programmes funded by Member Associations; and establish a network of contacts among people responsible for or interested in health education in leprosy programmes.

In 1989 an Expert Group on Health Education was established to provide a focal point for ILEP on the above. The Group is part of the ILEP Medical Commission Training Discipline and works closely with TALMILEP. The Group welcomes information on health education from national leprosy programmes, including particular needs and encourages the establishment of regional task forces to work in depth on some of the issues raised in this article.*

22 Avenue Hellevelt

L G VAN PARIJS

\section{Brussels}

Belgium

* Contact addresses of the Expert Group in Health Education: L G Van Parijs, Chairman, 22 Avenue Hellevelt, 1180 Brussels, Belgium, and J Neville, Convenor, TLMI, 80 Windmill Road, Brentford, Middlesex TW8 0QH, UK.

\section{References}

1 Jopling WH. Handbook of Leprosy (3d edition). London: Williams Heinemann Medical Books, 1984.

2 Thangaraj RH, Yawalkar SJ. Le prosy for medical practitioners and paramedical workers (3d ed.). Basle: CibaGeigy, 1988.

3 Pattyn SR, Dockx P, Capp JA. La Lèpre. Paris: Masson, 1981.

4 Bryceson A, Pfaltzgraff RE. Leprosy. London: Churchill Livingstone, 1979.

${ }^{5}$ Hastings RC (ed). Leprosy. London: Churchill Livingstone, 1985.

${ }^{6}$ Guidelines for the Campaign against Le prosy. London: ILEP, 1982.

7 Pearson JM. Essentials of Leprosy. Würzburg: GLRA, 1986.

${ }^{8}$ World Health Organization. A Guide to Leprosy Control (2nd ed). Geneva: WHO 1988.

9 Van Parijs LG. Health Education in Leprosy. A Manual for Health Workers. London: ILEP, 1986.

10 Neville J. A Guide to Health Education in Leprosy (4th ed). Addis Ababa: ALERT, 1980.

11 Watson JM. Preventing disability in leprosy patients. Brentford: The Leprosy Mission International, 1986.

12 Kaufman A, Senkenesh M, Neville J. The Social Dimension of Leprosy. London: ILEP, 1982.

13 Watzlawick P et al. Pragmatics of Human Communication. (4th edition). New York: Norton, 1987.

14 Stewart M, Roter D (eds). Communicating with medical patients. Sage Publ., London, 1989.

15 McDougall AC, Georgiev GD. Priorities in Leprosy Control. Lepr Rev, 1989; 60: 1-7.

16 Pre-congress workshop on health education. Brentford: The Leprosy Mission International, 1988.

17 National Training Institute for Leprosy. Leprosy Skill Book. Karachi: Marie Adelaïde Centre, undated.

18 Manual of Training. Multiple Drug Therapy for Leprosy. Department of Health. Leprosy Control Service, Manilla 1987.

19 Van Parijs LG. Health Education in Le prosy. A Manual for Health Workers. Supplements to Manual. London: ILEP, 1990.

20 Lennon J. A review of health education in leprosy. Int J Lepr, 1988; 56 (4): 611-18. 
21 Valencia L. Social science research on social dimensions of leprosy: where do we go from here? Int J Lepr, 1989; 57 (4): 847-63.

22 Neylan TC et al. Illness beliefs of Leprosy Patients: Use of medical anthropology in clinical practice. Int $J$ Lepr, 56 (2): 1988; 271-37.

23 Senkenesh GM. Summary of Social Research in Leprosy. Teaching notes ALERT, undated.

${ }^{24}$ Weisman AD. A model for psycho-social phasing in cancer in Moos RH (ed). Coping with physical illness: 2 : New Perspectives. New York: Plenum Medical Book Co, 1984.

${ }^{25}$ Cassell EJ. The nature of sufffering and the goals of medicine. $N$ Engl J Med, 1982; 306 (11): 639-45.

${ }^{26}$ Brieger, RB et al. Developing health education for oral rehydration therapy at a rural Nigerian clinic: Part 1. Pat Ed \& Counseling, 1988; 11: 189-202. 